\title{
A INFLUÊNCIA DE EMPRESAS COMERCIAIS ARTICULADAS EM REDE PARA A ORGANIZAÇÃO DAS PEQUENAS CIDADES NO TERRITÓRIO DE IDENTIDADE DO SISAL
}

Sara Raquel Leal B. dos Santos; Onildo Araújo da Silva

1. Bolsista PIBIC/CNPq, Graduando em Geografia, Universidade Estadual de Feira de Santana, e-mail: saraba_84@hotmail.com

2. Orientador, Departamento Ciências Humanas e Filosofia, Universidade Estadual de Feira de Santana, e-mail: fssilvafs@ hotmail.com

PALAVRAS-CHAVE: redes, cidades, empresas.

\section{INTRODUÇÃO}

A pesquisa teve como objetivo inicial identificar as empresas comerciais registradas nas pequenas cidades do Território do Sisal. Os dados estatísticos utilizados para identificar o número de empresas comerciais registradas nas pequenas cidades do Território do Sisal foram do IBGE, cidades (Instituto Brasileiro de Geografia e Estatística). O quadro a seguir apresenta o número de empresas cadastradas pelo IBGE nos 18 municípios que se enquadram como pequenas cidades do Território de Identidade do Sisal a saber Arací, Barrocas, Biritinga, Candeal, Cansanção, Ichu, Itiúba, Lamarão, Monte Santo, Nordestina, Queimadas, Quijingue, Retirolândia, Santaluz, São Domingos, Teofilândia, Tucano e Valente.

\section{MATERIAL E MÉTODOS OU METODOLOGIA}

Para a pesquisa em questão, inicialmente fizemos pesquisas bibliográficas dos principais autores que discutem os conceitos apresentados, a saber espaço, território e redes, assim como pesquisas em meios digitais para levantamento de dados sobre as empresas comerciais nas pequenas cidades no espaço em questão. A proposta inicial foi aplicar questionários com os proprietários das principais redes comerciais no Território do Sisal, para então elaborar as bases cartográficas, planilhas, construir artigos e o relatório. Nos atemos a aplicação de questionário com a gerente da agência da Receita Federal.

\section{RESULTADOS E/OU DISCUSSÃO}

Dentre as empresas cadastradas acima pelo IBGE (Cadastro central) foram identificadas empresas comerciais no Território de Identidade do Sisal, o que constitui-se como um dos objetivos específicos da pesquisa. Os dados utilizados para apresentar estatisticamente a quantidade de empresas comerciais no Território do Sisal foi a base do CNAE/IBGE (Classificação Nacional de Atividade Econômica). A CNAE, 
oficialmente adotada pelo sistema estatístico nacional, classifica e divide as atividades econômicas no Brasil em 21 seções que obedecem uma sequência da letra A à letra U. A seção $G$, referente a atividades econômicas do comércio, reparação de veículos automotores e motocicletas foi a seção utilizada para a pesquisa em questão. O quadro abaixo apresenta o número de empresas cadastradas no Cadastro Central de Empresas (CEMPRE). O CEMPRE é formado por empresas, organizações e suas respectivas unidades locais constituídas oficialmente, as quais se encontram registradas no Cadastro Nacional de Pessoa Jurídica (CNPJ). A atualização do cadastro das empresas comerciais e dos demais ramos ocorre anualmente a partir das pesquisas econômicas do IBGE.

EMPRESAS COMERCIAIS E REPARAÇÃO DE VEÍCULOS AUTOMOTORES E MOTOCICLETAS (2006-2012)

\begin{tabular}{|l|r|r|r|r|r|r|r|}
\hline \multirow{2}{*}{ Municípios } & \multicolumn{7}{|c|}{ Anos } \\
\cline { 2 - 9 } & \multicolumn{2}{|l}{2006} & \multicolumn{2}{|l|}{2007} & 2009 & 2010 & 2011 \\
\hline Araci & $\mathbf{2 0 7}$ & $\mathbf{2 2 8}$ & $\mathbf{1 8 6}$ & $\mathbf{2 4 1}$ & $\mathbf{2 8 4}$ & $\mathbf{3 2 0}$ & $\mathbf{2 7 9}$ \\
\hline Barrocas & 101 & 79 & 92 & 92 & 100 & 98 & 101 \\
\hline Biritinga & 36 & 41 & 39 & 51 & 51 & 52 & 52 \\
\hline Candeal & 17 & 20 & 21 & 20 & 19 & 27 & 26 \\
\hline Cansanção & 129 & 141 & 238 & 199 & 213 & 279 & 274 \\
\hline Ichu & 46 & 39 & 38 & 50 & 51 & 49 & 38 \\
\hline Itiúba & 125 & 83 & 152 & 155 & 158 & 159 & 153 \\
\hline Lamarão & 21 & 15 & 14 & 15 & 16 & 22 & 20 \\
\hline Monte Santo & 175 & 174 & 209 & 193 & 247 & 265 & 255 \\
\hline Nordestina & 41 & 49 & 58 & 55 & 71 & 81 & 85 \\
\hline Queimadas & 101 & 104 & 142 & 159 & 162 & 174 & 172 \\
\hline Quijingue & 109 & 107 & 114 & 98 & 125 & 128 & 132 \\
\hline Retirolândia & 91 & 112 & 108 & 119 & 153 & 154 & 111 \\
\hline Santaluz & 102 & 102 & 167 & 212 & 241 & 299 & 331 \\
\hline São Domingos & 52 & 61 & 70 & 78 & 80 & 81 & 85 \\
\hline Teofilândia & 99 & 77 & 102 & 78 & 102 & 102 & 106 \\
\hline Tucano & $\mathbf{2 8 4}$ & $\mathbf{2 9 5}$ & $\mathbf{3 1 0}$ & $\mathbf{3 7 9}$ & $\mathbf{3 7 3}$ & $\mathbf{3 4 4}$ & $\mathbf{3 5 1}$ \\
\hline Valente & 152 & 226 & 229 & 250 & 308 & 288 & 269 \\
\hline
\end{tabular}

Fonte: SIDRA- IBGE, Elaborado pelo autor

O número de empresas comerciais, de veículos automotores e motocicletas registrados entre os anos de 2006 à 2012 nas pequenas cidades do Território de Identidade do Sisal é significativo. Dentre os 18 municípios, destacam-se Tucano e Arací, com maior número de empresas comerciais registradas pelo IBGE.

Dentre as pequenas cidades do Território do Sisal, o município de Tucano registrou entre os anos de 2006 a 2012 maior número de empresas comerciais cadastradas pelo IBGE. O ano em que pode ser verificado maior número de empresas cadastradas nesse município foi 2011 com 320 empresas cadastradas. 
A pesquisa tem como segundo objetivo específico identificar a partir do número de filiais, redes de empresas comerciais nas pequenas cidades do Território de Identidade do Sisal. Esses dados não foram possíveis de serem coletados através do site do IBGE. Em viagem de campo aos 18 municípios do Território identificamos no município de Arací a Farmácia do Trabalhador, o Supermercado G Barbosa, no município de Valente identificamos um comércio mais consolidado. Em outro municípios verificamos comércios ainda incipientes, ou que não se expandiram como é o caso do município de Queimadas e Candeal. Os 18 municípios caracterizam-se por ter o foco do comércio localizado em uma praça principal que no geral possuem pouca variedade de lojas comerciais.

A pesquisa tem como terceiro objetivo específico compreender as práticas espaciais das empresas comerciais. A partir de visita de campo observamos que as empresas comerciais se organizam espacialmente, no geral próximas a prédios públicos, como cartórios e prefeituras, prédios de grandes empresas privadas, igrejas, sindicatos e feiras livres.

\section{CONCLUSÕES}

As pequenas cidades do Território de Identidade do Sisal possuem forte influência do seu entorno rural, e uma imediata articulação com a produção da agrave sisaleira. Nos dados sobre produção agrícola fornecidos pelo IBGE, a agrave sisaleira é apresentada como a segunda maior produção agrícola entre os anos de 2004 a 2014. Também segundo o IBGE 2001, mais de 50\% da população dos 18 municípios analisados no Território de Identidade do Sisal residem em áreas rurais.

As empresas comerciais identificadas nos municípios do Território são predominantes, algumas inclusive já atuam em rede de empresas com unidades em várias pequenas cidades. Também se verifica uma diversidade no número de empresas e na diversificação do comércio, a exemplo de cidades como Valente e Candeal, por exemplo.

\section{REFERÊNCIAS}

ANDRADE M.C. O Nordeste e a questão regional. São Paulo: ÁTICA, 1988.

CARLOS, A F. A 1996. O Lugar no/do Mundo. São Paulo. Hucitec. 150 p.

COELHO NETO, Agripino Souza. Emergência e atuação das redes de coletivos sociais organizados no Território do Sisal. COELHO NETO. AS; SANTOS, EMC; SILVA, OA (Orgs.).(Geo) grafias dos movimentos sociais. Feira de Santana: UEFS Editora, 2010. 
CORRÊA, Roberto Lobato. Região e organização espacial. Ática, 1987.

CORRÊA, Roberto Lobato. O espaço geográfico: algumas considerações. In: SANTOS, Milton (Org.). Novos rumos da Geografia brasileira. São Paulo: Hucitec, 1982.

MOREIRA, Ruy. Repensando a Geografia. In: SANTOS, Milton (Org.). Novos rumos da Geografia brasileira. São Paulo: Hucitec, 1982.

OLIVEIRA, Ariovaldo Umbelino de. Modo capitalista de produção e agricultura. São Paulo: Ática, 1986. (Série Princípios).

OLIVEIRA, Ariovaldo Umbelino de. A agricultura camponesa no Brasil. São Paulo: Contexto, 1991. (Coleção Caminhos da Geografia).

SANTOS, Milton. A natureza do espaço: técnica e tempo, razão e emoção. 3 ed. São Paulo: Hucitec, 1999.

SANTOS, Milton \& SILVEIRA, Maria Laura. O Brasil: território e sociedade no início do século XXI. Rio de Janeiro/ São Paulo: Record, 2001.

SANTOS, E. M. S.; SILVA, O. A. COELHO NETO, A. S.; Gente ajudando gente: o tecido associativista do Território do Sisal. Feira de Santana: UEFS Editora, 2011.

SANTOS, M. Técnica, espaço, tempo: globalização e meio técnico científico informacional. São Paulo: HUCITEC, 1998.

SILVA, José Graziano da. A nova dinâmica da agricultura brasileira. Campinas, SP: Unicamp. IE. 1998.

SILVA, José Graziano da. A modernização dolorosa. Estrutura agrária, fronteiras agrárias e trabalhadores rurais. Rio de Janeiro: Zahar Editores, 1982.

SILVA, O. A. A influência recíproca na ação: o Estado e as associações no Território do Sisal. In: COELHO NETO, A. S.; SANTOS, E. M. S.; SILVA, O. A. (Geo)grafias dos movimentos sociais. Feira de Santana: UEFS Editora, 2010.

SILVA, O. A. A parceria Estado/associações e as políticas públicas para convivência com o semiárido no território do sisal no estado da Bahia. CGB, 2014.

SILVA, O. A. da; SANTO, E. M. C. Associativismo e desenvolvimento local: o caso da APAEB no município de Valente- Estado da Bahia (Brasil). In El Dosarrollo Local em su Complejidad. Santiago de Compostela: USC, 2005.

SILVA, Álvaro Luis Vasconcelos et ali. APAEB: Uma História de Fibra, Luta e Subsistência. Valente, APAEB, 1993.

SUPERINTENDÊNCIA DO DESENVOLVIMENTO DO NORDESTE. As Secas do Nordeste: uma abordagem histórica de causa e efeito. Recife: SUDENE, 1981. 